\title{
BMR
}

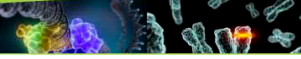

\section{Alkaline phosphatase activity in salivary gland cells of Rhodnius neglectus and R. prolixus (Hemiptera, Triatominae)}

\author{
A.P.M. Lima-Oliveira ${ }^{1}$, K.C.C. Alevi ${ }^{1}$, A.C.B. Anhê $\hat{e}^{2}$ and \\ M.T.V. Azeredo-Oliveira ${ }^{1}$ \\ ${ }^{1}$ Laboratório de Biologia Celular, Departamento de Biologia, \\ Instituto de Biociências, Letras e Ciências Exatas, \\ Universidade Estadual Paulista "Júlio de Mesquita Filho", \\ São José do Rio Preto, SP, Brasil \\ ${ }^{2}$ Departamento de Engenharia Ambiental, \\ Instituto de Ciências Tecnológicas e Exatas, \\ Universidade Federal do Triângulo Mineiro, Uberaba, MG, Brasil \\ Corresponding author: K.C.C. Alevi \\ E-mail: kaiochaboli@hotmail.com
}

Genet. Mol. Res. 15 (3): gmr.15038339

Received December 23, 2015

Accepted February 11, 2016

Published July 29, 2016

DOI http://dx.doi.org/10.4238/gmr.15038339

Copyright $(C 2016$ The Authors. This is an open-access article distributed under the terms of the Creative Commons Attribution ShareAlike (CC BY-SA) 4.0 License.

ABSTRACT. Alkaline phosphatase activity was detected in salivary gland cells of the Rhodnius neglectus Lent, 1954, and R. prolixus Stal, 1859, vectors of Trypanosoma cruzi Chagas, 1909 (etiological agent of Chagas disease) and T. rangeli Tejera, 1920 (pathogenic to insect). The Gomori technique was used to demonstrate alkaline phosphatase activity. Alkaline phosphatase activity was observed throughout the entire gland, with an increased activity in the posterior region of the principal gland. In particular, phosphatase activity was found in the nucleolar corpuscles, suggesting a relationship with the rRNA 
transcription and ribosomal biogenesis. Alkaline phosphatase was also detected in the nuclear membrane and nuclear matrix, suggesting an association with the nucleo-cytoplasmic transport of ribonucleoproteins and the mechanisms of cell cycle and DNA replication, respectively. This study highlights the importance of alkaline phosphatase in the salivary gland of $R$. prolixus and $R$. neglectus and emphasizes its importance in secretory activity. Secretory activity is directly involved in hematophagy and, consequently, in development during metamorphosis. The observed presence of alkaline phosphatase suggests its involvement in the production of saliva allowing feeding of these insects that are important vectors of Chagas disease.

Key words: Cytochemistry; Hematophagy; Triatominae subfamily

\section{INTRODUCTION}

Triatomines (Hemiptera, Heteroptera, Reduviidae, Triatominae) are vectors of two protozoa: Trypanosoma cruzi Chagas, 1909, and T. rangeli Tejera, 1920. T. cruzi is an etiological agent of Chagas disease, a disease endemic to Latin America, which affects about 7 to 8 million people in the world (WHO, 2014). T. rangeli is considered pathogenic only to the insect itself and can prejudice the gut, Malpighian tubules, cuticle, trachea, salivary glands, and nervous system (Vallejo et al., 2009).

Triatominae is comprised of six tribes, namely, Alberproseniini, Bolboderini, Cavernicolini, Linshcosteini, Rhodniini, and Triatomini (Alevi et al., 2013). Rhodniini comprises two genera (Rhodnius and Psammolestes) and 22 species (19 of Rhodnius and 3 of Psammolestes) (Abad-Franch et al., 2013; Alevi et al., 2013).

Triatomines are hematophagous insects. They have a gland that produces saliva, which is constantly released during the blood meal. This saliva is necessary for localization of the blood within the blood vessel, as well as the ingestion of blood to maintain the flux (Ribeiro, 1987; Law et al., 1992; Soares et al., 2006). It is secreted in order to antagonize hemostatic, inflammatory, and immunologic systems imposed by the host (Ribeiro and Francischetti, 2003).

In Rhodnius, the salivary gland is composed of two units: the principal (reddish, elongated, and bigger) and accessory (translucent and rounded) units. These structures have been studied anatomically, histologically (Lacombe, 1999), cytogenetically (Anhê and Azeredo-Oliveira, 2008; Anhê et al., 2014), and biochemically (Anhê et al., 2007).

These insects are hematophagous and strict repast is fundamental for the molts occur. Therefore, this paper aimed to describe the activity of alkaline phosphatase in the cells of the $R$. neglectus Lent, 1954, and R. prolixus Stal, 1859, salivary glands that are so important for the feeding and development of these vectors.

\section{MATERIAL AND METHODS}

The Gomori technique (Gomori, 1952) was used to identify alkaline phosphatase, whose activity is at $\mathrm{pH}$ between 9.0 and 9.6. Unfixed whole salivary glands of adult, male and female $R$. neglectus and $R$. prolixus were studied. The salivary glands of 30 insects (15 males and 15 females) of each species were analyzed. They had been assigned by the

Genetics and Molecular Research 15 (3): gmr.15038339 
"Triatominae Insectarium" at the Departamento de Ciências Biológicas na Faculdade de Ciências Farmacêuticas (FCFAR/UNESP), Câmpus Araraquara (Insetário de Triatominae, UNESP - Araraquara, São Paulo). The material was incubated in a medium containing sodium $\beta$-glycerophosphate substrate. Calcium chloride and magnesium sulfate were used to activate the enzyme. The enzyme released phosphate from the substrate, which reacts with the calcium ions resulting in calcium phosphate. This, treated with cobalt nitrate, was converted to cobalt phosphate. Subsequently, the material was incubated in a $1 \%$ ammonium sulfide solution and was converted to cobalt sulfide, which was observed through a light microscope as a dense and dark granular accumulation.

At the same time, a control reaction was performed using two incubation media: 1) without the sodium $\beta$-glycerophosphate substrate and 2) with substrate but without magnesium sulfate. The preparations were examined with a Zeiss Jenaval photomicroscope and photographed. The negatives were developed and printed in specialized laboratories.

\section{RESULTS}

Males and females of both species showed similar alkaline phosphatase activity in their salivary gland cells. Figure 1 shows a general view of the salivary gland of Rhodnius subjected to the alkaline phosphatase technique. The cobalt sulfide precipitation, the final product of the reaction, was more evident in the posterior region of the principal gland. In both species and sexes, the nuclei showed evident enzymatic activity on the nucleolar corpuscles (as granules) as well as in the nuclear matrix (Figure 2A and C). In addition, the nuclear and plasmatic membranes showed intense alkaline phosphatase activity (indicated by arrows in Figure 2C). When the sodium $\beta$-glycerophosphate substrate (Figure $2 \mathrm{~B}$ ) or magnesium sulfate (Figure 2D) were absent, the glands showed a total absence of enzyme activity.

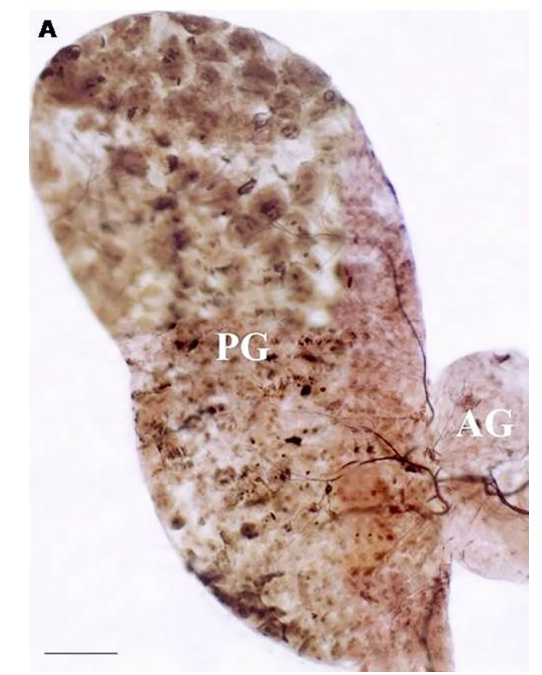

Figure 1. Salivary gland of a female Rhodnius neglectus subjected to a cytochemical reaction for alkaline phosphatase identification in the principal (PG) and accessory (AG) glands. Note that the alkaline phosphatase activity is observed in the whole gland, with a more intense activity in the posterior region of the principal gland. Bar: $10 \mu \mathrm{m}$.

Genetics and Molecular Research 15 (3): gmr.15038339 

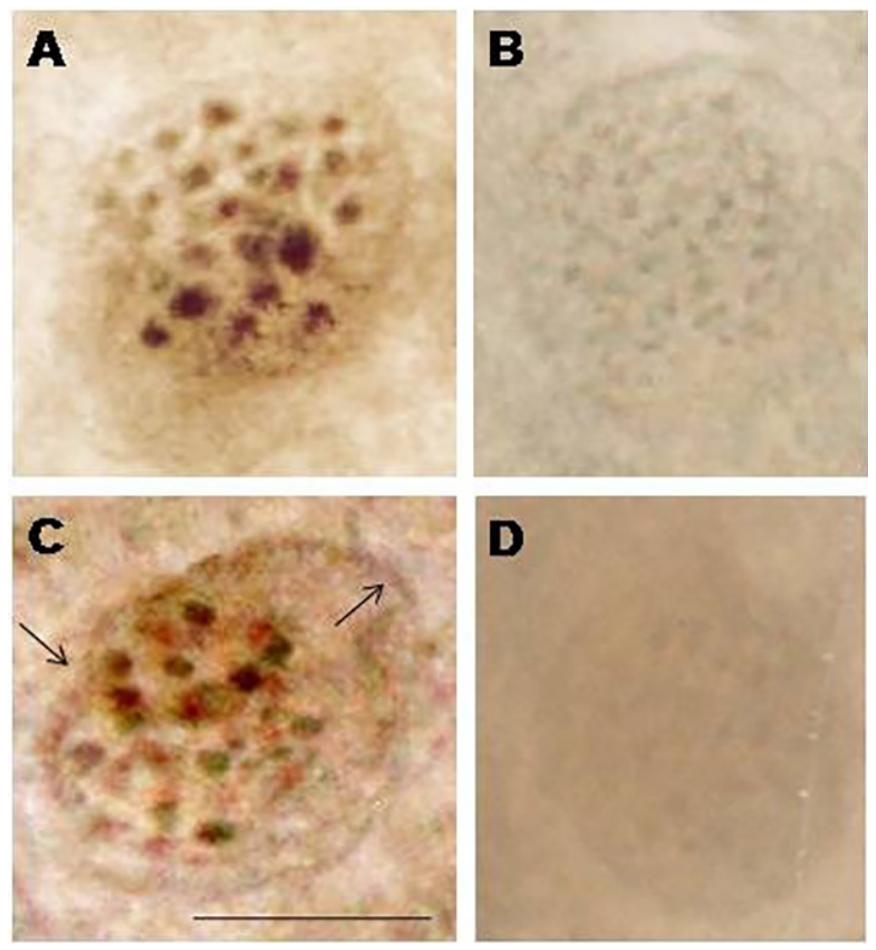

Figure 2. Salivary gland of Rhodnius neglectus and R. prolixus subjected to cytochemical reaction for alkaline phosphatase (A. and C.) and controls (B. and D.). Note the alkaline phosphatase activity in the nucleolar corpuscles, nuclear matrix (A and C) and nuclear membranes (C, arrows). With the control techniques without sodium $\beta$-glycerophosphate substrate (B) or without magnesium sulfate (D), there was a total absence of enzyme activity. Bar: $10 \mu \mathrm{m}$.

\section{DISCUSSION}

Alkaline phosphatase activity was found in the salivary gland of both sexes of $R$. prolixus and $R$. neglectus. This phosphatase, whose activity has been studied in many insects, is involved in many vital biochemical pathways (Eguchi, 1995). Alkaline phosphatase has been found to be widely distributed in the gastrointestinal tract, salivary glands, and Malpighian tubules of both nymphs and adult insects (Srivastava and Saxena, 1967). The most intense response of this cytochemical technique was detected in the cell nuclei of the Rhodnius salivary gland. This agrees with the results obtained by Azeredo-Oliveira and Mello (1986) in the Malpighian tubules of Triatoma infestans Klug, 1843. According to Azeredo-Oliveira and Mello (1986), alkaline phosphatase activity found in the nuclei might be related to transcription phenomena and cell metabolism. This hypothesis can also be applied to the present study, since alkaline phosphatase activity was found in nucleolar corpuscles. Furthermore acid phosphatase is another enzyme too described in nucleolus (Anhê et al., 2007), which suggests that this enzyme is active during rRNA molecule transcription (Anhê et al., 2007). Alkaline phosphatase has also been found to be associated with cell membranes in the medium intestine of $R$. prolixus (Ferreira et al., 1988). Wolfersberger (1984) suggested that alkaline phosphatase 
is a typical marker enzyme, and it was detected mainly in the intestinal microvilosities based on the markings. In the present study, alkaline phosphatase activity was also observed in the plasmatic and nuclear membranes. This may be related with intercellular and intracellular transports. This activity in the transport of substances, through biological membranes, has been observed in several other studies (Haussler et al., 1970; Cutler et al., 1974; Ferreira and Terra, 1980; Azeredo-Oliveira and Mello, 1986). Hence, the finding of alkaline phosphatase in the nuclear membrane of the triatomine salivary gland cells was expected, since this structure is a place for nucleo-cytoplasmic exchange (Feldherr, 1965). Cutler et al. (1974) demonstrated that, ultrastructurally, the alkaline phosphatase activity in the nuclear membrane was located in the nuclear pores.

Alkaline phosphatase activity was found in the nucleoli, nuclear membrane, and nuclear matrix of salivary gland cells, suggesting relationships with the rRNA transcription and ribosomal biogenesis, nucleo-cytoplasmic transport of ribonucleoproteins, and the mechanisms of cell cycle and DNA replication, respectively. The presence of alkaline phosphatase in the plasmatic membranes suggests a role in the intercellular transport of molecules. These processes are directly involved with the activity of gland secretion.

The difference in reactivity found between the anterior and posterior regions of the gland may be associated with differences in metabolism and physiology. It may also be related to the biosynthesis of different secretions that assist in hematophagy and, as such, in the development of these insects of epidemiological importance.

This study highlights the importance of alkaline phosphatase in the salivary gland of $R$. prolixus and $R$. neglectus and emphasizes its importance in secretory activity. Alkaline phosphatase activity is directly involved in hematophagy and consequently in insect development during metamorphosis. The presence of alkaline phosphatase may be related to the production of saliva that allow feeding of these insects that are important vectors of Chagas disease.

\section{Conflicts of interest}

The authors declare no conflict of interest.

\section{ACKNOWLEDGMENTS}

The authors are grateful to Dr. José M. Soares Barata, and to the technicians, João Luís Molina Gil and Bento Gregório de Jesus, for providing the specimens studied. The financial support of CNPq is gratefully acknowledged.

\section{REFERENCES}

Abad-Franch F, Pavan MG, Jaramillo-O N, Palomeque FS, et al. (2013). Rhodnius barretti, a new species of Triatominae (Hemiptera: Reduviidae) from western Amazonia. Mem. Inst. Oswaldo Cruz 108 (Suppl 1): 92-99. http://dx.doi. org $/ 10.1590 / 0074-0276130434$

Alevi KCC, Rosa JA and Azeredo Oliveira MTV (2013). Mini review: Karyotypic survey in Triatominae subfamily (Hemiptera, Heteroptera). Entomol. Ornithol. Herpetol. 2: 106. http://dx.doi.org/10.4172/2161-0983.1000106

Anhê AC and Azeredo-Oliveira MT (2008). Cytochemical characterization of Triatoma infestans and Panstrongylus megistus salivary gland cells (Hemiptera, Reduviidae, Triatominae). Micron 39: 1126-1133. http://dx.doi. org/10.1016/j.micron.2008.06.003

Genetics and Molecular Research 15 (3): gmr.15038339 
A.P.M. Lima-Oliveira et al.

Anhê AC, Lima-Oliveira AP and Azeredo-Oliveira MT (2007). Acid phosphatase activity distribution in salivary glands of triatomines (Heteroptera, Reduviidae, Triatominae). Genet. Mol. Res. 6: 197-205.

Anhê ACBM, Lima-Oliveira APM and Azeredo-Oliveira MTV (2014). Cytochemical study of Rhodnius neglectus and Rhodnius prolixus salivary gland cells (Hemiptera, Triatominae). Iheringia Sér. Zool. 104: 399-403.

Azeredo-Oliveira MTV and Mello MLS (1986). Detecção da atividade fosfatásica alcalina em túbulos de Malpighi de Triatoma infestans Klug. Cienc. Cult. 38: 1870-1874.

Cutler LS, Chaudhry AP and Montes M (1974). Alkaline phosphatase activity associated with the nuclear pore in normal and neoplastic salivary gland tissue. J. Histochem. Cytochem. 22: 1113-1117. http://dx.doi.org/10.1177/22.12.1113

Eguchi M (1995). Alkaline phosphatase isozymes in insects and comparison with mammalian enzyme. Comp. Biochem. Physiol. B Biochem. Mol. Biol. 111: 151-162. http://dx.doi.org/10.1016/0305-0491(94)00248-S

Feldherr CM (1965). The effect of the electron-opaque pore material on exchanges through the nuclear annuli. J. Cell Biol. 25: 43-53. http://dx.doi.org/10.1083/jcb.25.1.43

Ferreira C and Terra WR (1980). Intracellular distribution of hydrolases in midgut caeca cells from an insect with emphasis on plasma membrane-bound enzymes. Comp. Biochem. Physiol. 66: 467-473.

Ferreira C, Ribeiro AF, Garcia ES and Terra WR (1988). Digestive enzymes trapped between and associated with the double plasma membranes of Rhodnius prolixus posterior midgut cells. Insect Biochem. 18: 521-530. http://dx.doi. org/10.1016/0020-1790(88)90003-0

Gomori O (1952). Microscopic histochemistry; principles and practice. Chicago University Press, Chicago, 266.

Haussler M, Nagode LA and Rasmussen H (1970). Induction of intestinal brush border alkaline phosphatase by vitamin D and identity with ca-ATPase. Nature 228: 1199-1201. http://dx.doi.org/10.1038/2281199a0

Lacombe D (1999). [Anatomy and histology of salivary glands of Triatominae]. Mem. Inst. Oswaldo Cruz 94: 557-564. http://dx.doi.org/10.1590/S0074-02761999000400023

Law JH, Ribeiro JM and Wells MA (1992). Biochemical insights derived from insect diversity. Annu. Rev. Biochem. 61: 87-111. http://dx.doi.org/10.1146/annurev.bi.61.070192.000511

Ribeiro JM (1987). Role of saliva in blood-feeding by arthropods. Annu. Rev. Entomol. 32: 463-478. http://dx.doi. org/10.1146/annurev.en.32.010187.002335

Ribeiro JMC and Francischetti IM (2003). Role of arthropod saliva in blood feeding: sialome and post-sialome perspectives. Annu. Rev. Entomol. 48: 73-88. http://dx.doi.org/10.1146/annurev.ento.48.060402.102812

Soares AC, Carvalho-Tavares J, Gontijo NdeF, dos Santos VC, et al. (2006). Salivation pattern of Rhodnius prolixus (Reduviidae; Triatominae) in mouse skin. J. Insect Physiol. 52: 468-472. http://dx.doi.org/10.1016/j. insphys.2006.01.003

Srivastava JP and Saxena SC (1967). On the alkaline and acid phosphatase in the alimentary tract of Periplaneta americana L. (Blattaria: Blattidae). Appl. Entomol. Zool. (Jpn.) 2: 85-92.

Vallejo GA, Guhl F and Schaub GA (2009). Triatominae-Trypanosoma cruzi/T. rangeli: Vector-parasite interactions. Acta Trop. 110: 137-147. http://dx.doi.org/10.1016/j.actatropica.2008.10.001

WHO (2014). Chagas disease (American trypanosomiasis). http://www.who.int/mediacentre/factsheets/fs340/en/. Accessed November 8, 2014.

Wolfersberger MG (1984). Enzymology of plasma membranes of insect intestinal cells. Am. Zool. 24: 187-197. http:// dx.doi.org/10.1093/icb/24.1.187

Genetics and Molecular Research 15 (3): gmr.15038339 